\title{
Robot-assisted Kidney Transplantation: The European Experience
}

\author{
Alberto Breda $^{a, *}$, Angelo Territo $^{a}$, Luis Gausa $^{a}$, Volkan Tuğcu $^{b}$, Antonio Alcaraz $^{c}$, \\ Mireia Musquera ${ }^{c}$, Karel Decaestecker ${ }^{d}$, Liesbeth Desender $^{e}$, Michael Stockle $^{f}$, Martin Janssen $^{f}$, \\ Paolo Fornara $^{g}$, Nasreldin Mohammed $^{g}$, Giampaolo Siena $^{h}$, Sergio Serni ${ }^{h}$, Luis Guirado $^{i}$, \\ Carma Facundo ${ }^{i}$, Nicolas Doumerc ${ }^{j}$
}

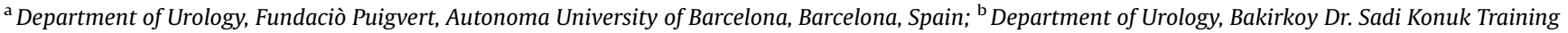
and Research Hospital, Istanbul, Turkey; ${ }^{\mathrm{c}}$ Department of Urology, Hospital Clinic, Barcelona, Spain; ${ }^{\mathrm{d}}$ Department of Urology, Ghent University Hospital, Ghent, Belgium; ${ }^{\mathrm{e}}$ Department of Thoracic and Vascular Surgery, Ghent University Hospital, Ghent, Belgium; ${ }^{\mathrm{f}}$ Department of Urology, University Saarland, Homburg/Saar, Germany; ${ }^{\mathrm{g}}$ Department of Urology, University Hospital Halle (Saale), Halle, Germany; ${ }^{\mathrm{h}}$ Department of Urology, University of Florence, Careggi Hospital, Florence, Italy; ${ }^{\mathrm{i}}$ Department of Nephrology, Fundaciò Puigvert, Autonoma University of Barcelona, Barcelona, Spain; ${ }^{\mathrm{j}}$ Department of Urology and Renal Transplantation, University Hospital of Rangueil, Toulouse, France

\section{Article info}

\section{Article history:}

Accepted August 27, 2017

\section{Associate Editor: \\ Giacomo Novara \\ Statistical Editor: \\ Andrew Vickers}

\section{Keywords:}

Kidney transplantation

Regional hypothermia

Robot-assisted kidney

transplantation

Robotic surgery

Vascular anastomosis

\section{EU * ACME}

www.eu-acme.org/

europeanurology

Please visit www.eu-acme.org/ europeanurology to read and answer questions on-line. The EU-ACME credits will then be attributed automatically.

\begin{abstract}
Background: Robot-assisted kidney transplantation (RAKT) has recently been introduced to reduce the morbidity of open kidney transplantation (KT).

Objective: To evaluate perioperative and early postoperative RAKT outcomes.

Design, setting and participants: This was a multicenter prospective observational study of 120 patients who underwent RAKT, predominantly with a living donor kidney, in eight European institutions between July 2015 and May 2017, with minimum follow-up of 1 mo. The robot-assisted surgical steps were transperitoneal dissection of the external iliac vessels, venous/arterial anastomosis, graft retroperitonealization, and ureterovesical anastomosis.

Outcome measurements and statistical analysis: Descriptive analysis of surgical data and their correlations with functional outcomes.

Results and limitations: The median operative and vascular suture time was 250 and $38 \mathrm{~min}$, respectively. The median estimated blood loss was $150 \mathrm{ml}$. No major intraoperative complications occurred, although two patients needed open conversion. The median postoperative estimated glomerular filtration rate was $21.2,45.0,52.6$, and $58.0 \mathrm{ml} / \mathrm{min}$ on postoperative day $1,3,7$, and 30 , respectively. Both early and late graft function were not related to overall operating time or rewarming time. Five cases of delayed graft function $(4.2 \%)$ were reported. One case $(0.8 \%)$ of wound infection, three cases $(2.5 \%)$ of ileus, and four cases of bleeding (3.3\%; three of which required blood transfusion), managed conservatively, were observed. One case $(0.8 \%)$ of deep venous thrombosis, one case $(0.8 \%)$ of lymphocele, and three cases $(2.5 \%)$ of transplantectomy due to massive arterial thrombosis were recorded. In five cases (4.2\%), surgical exploration was performed for intraperitoneal hematoma. Limitations of the study include selection bias, the lack of an open control group, and failure to report on patient cosmetic satisfaction.

Conclusions: When performed by surgeons with robotic and KT experience, RAKT is safe and reproducible in selected cases and yields excellent graft function.

Patient summary: We present the largest reported series on robot-assisted kidney transplantation. Use of a robotic technique can yield low complication rates, rapid recovery, and excellent graft function. Further investigations need to confirm our promising data.

(c) 2017 European Association of Urology. Published by Elsevier B.V. All rights reserved.

* Corresponding author. Department of Urology, Fundaciò Puigvert, Calle Josep Canaleta 17,

Barcelona 08035, Spain. Tel. +34 934 169700; Fax: +34 618179179.

E-mail address: albbred@hotmail.com (A. Breda).
\end{abstract}




\section{Introduction}

Kidney transplantation (KT) is considered the preferred treatment for patients with end-stage renal disease (ESRD) owing to the greater survival rate and better quality of life in comparison to hemodialysis [1]. Although the open approach remains the gold standard, minimally invasive techniques have been introduced to decrease the morbidity and mortality of open surgery [2], which could be especially important in immunocompromised and fragile KT patients. In 2002 Hoznek et al [3] described the possibility of performing a robotic anastomosis in KT, and in 2010 the first pure RAKT was performed by Giulianotti et al [4] in the USAs. One of the major challenges in RAKT was to keep the kidney cool during vascular anastomosis. Therefore, in 2014 Menon et al [5] standardized the technique with the transperitoneal approach and regional hypothermia. The authors highlighted that RAKT is a safe technique with possible advantages such as low intra- and postoperative complications, better cosmetic results, and superlative vision that could result in better quality of the vascular and ureteral anastomoses. In Europe, the first RAKT was performed by Boggi et al [6] in 2011 as a hybrid case with robotic vascular anastomosis and open ureterovesical anastomosis. The first two European pure RAKTs were performed in July 2015 by Doumerc et al [7] and Breda et al [8]. A year later, Breda et al [9] reported surgical and functional outcomes for 17 patients undergoing RAKT. Starting from these preliminary pure RAKT results, a European Robotic Urological Society (ERUS) RAKT group was created with the aim of collecting prospective data on RAKT in a common database.

The primary objective of this study was to evaluate perioperative and early postoperative surgical outcomes for RAKT performed in eight European institutions. Secondary objectives included functional outcomes and correlations between surgical data and functional results.

\section{Patients and methods}

\subsection{Study design}

This was a multicenter prospective observational study on RAKT predominantly from living donors performed at eight European centers (Table 1). The project was integrated in the ERUS RAKT working group to collect prospective data on RAKT.

\subsection{Study sample}

Data for 120 nonconsecutive patients undergoing RAKT were prospectively collected between July 2015 and May 2017 following institutional review board approval and patient informed consent. Computed tomography was performed for both recipients and donors to identify renal vascular anomalies and iliac artery atherosclerosis. The inclusion criteria were: patients with ESRD (considered as glomerular filtration rate [GFR] $<20 \mathrm{ml} / \mathrm{min}$ and/or symptomatic uremia and/or need for dialysis); a matched living or deceased donor; $>18 \mathrm{yr}$ of age; and body mass index (BMI) $\leq 40 \mathrm{~kg} / \mathrm{m}^{2}$. The exclusion criteria were: iliac artery atherosclerosis; malignancy; positive virology; severe comorbidity (cardiovascular, pulmonary, or hepatic); highly complex vascular
Table 1 - Robot-assisted kidney transplantations (RAKTs) carried out at European centers

\begin{tabular}{lc}
\hline Institution & RAKTs \\
& $(n)$ \\
\hline Fundació Puigvert, Barcelona, Spain (pilot center) & 20 \\
Bakirkoy Sadi Konuk Training and Research Hospital Center Turkey & 45 \\
Hospital Clinic, Barcelona, Spain & 23 \\
University Hospital of Rangueil, Toulouse, France & 10 \\
University Hospital Halle (Saale), Halle, Germany & 10 \\
Ghent University Hospital, Ghent, Belgium & 6 \\
University Saarland, Homburg/Saar, Germany & 4 \\
University of Florence, Careggi Hospital Florence, Italy. & 2 \\
Total & $\mathbf{1 2 0}$ \\
\hline
\end{tabular}

anatomy (ie, $>3$ arteries, $>1$ small accessory artery, $>2$ veins); multiple previous abdominal surgeries; previous transplant (second transplant); or simultaneous dual or multiple organ transplant.

\subsection{Study variables and outcomes}

Data for sociodemographic variables, surgical and functional outcomes, and early postoperative complications with minimum follow-up of $1 \mathrm{mo}$ were prospectively collected.

The surgical outcomes evaluated included cold and warm ischemia time and rewarming time. Warm ischemia time is the period between renal circulatory arrest and the beginning of cold storage; cold ischemia time is the duration of cold storage, with or without perfusion with a storage solution, before introduction of the graft into the recipient. Rewarming time is the time between removal of the kidney from cold storage and the start of reperfusion while continuously adding ice slush. Other surgical data analyzed were overall operative time, console time, vascular anastomosis time, ureteral reimplantation time, and estimated blood loss. Intraoperative complications included intraoperative vascular injuries, the need for vascular anastomosis revision, and conversion to open surgery in the event of massive bleeding or low blood flow on Doppler ultrasound evaluation. The early (30 d) postoperative complication rate was reported according to the Clavien-Dindo classification [10].

The functional outcomes considered were serum creatinine and estimated GFR (eGFR) on postoperative day (POD) 1, 3, 7, and 30. eGFR was calculated using the Modified Diet in Renal Disease equation (patient $>18$ yr old) [11,12]. Delayed graft function (DGF) was considered as a need for dialysis in the first postoperative week. Among the functional outcomes, we also included postoperative hemoglobin, evaluation of postoperative pain using a visual analog score (VAS), postoperative hospitalization, and time to double-J removal.

\subsection{Surgical procedure (Si/Xi da Vinci)}

The first standardization of RAKT was described by Menon et al [5] in the IDEAL phase 2a study. Following this technique, Breda et al [9] reported their first RAKT results with details of the technical aspects and surgical steps. The possible transvaginal introduction route has been described by Doumerc et al [8]. The surgical procedure was standardized in all participant centers. The main surgical steps are summarized and shown in Figures 1-5.

\subsection{Surgical experience}

All surgical teams involved in this study have thorough expertise in the field of robot-assisted surgery and open KT, with several hundred procedures of each approach performed. Before starting on human 

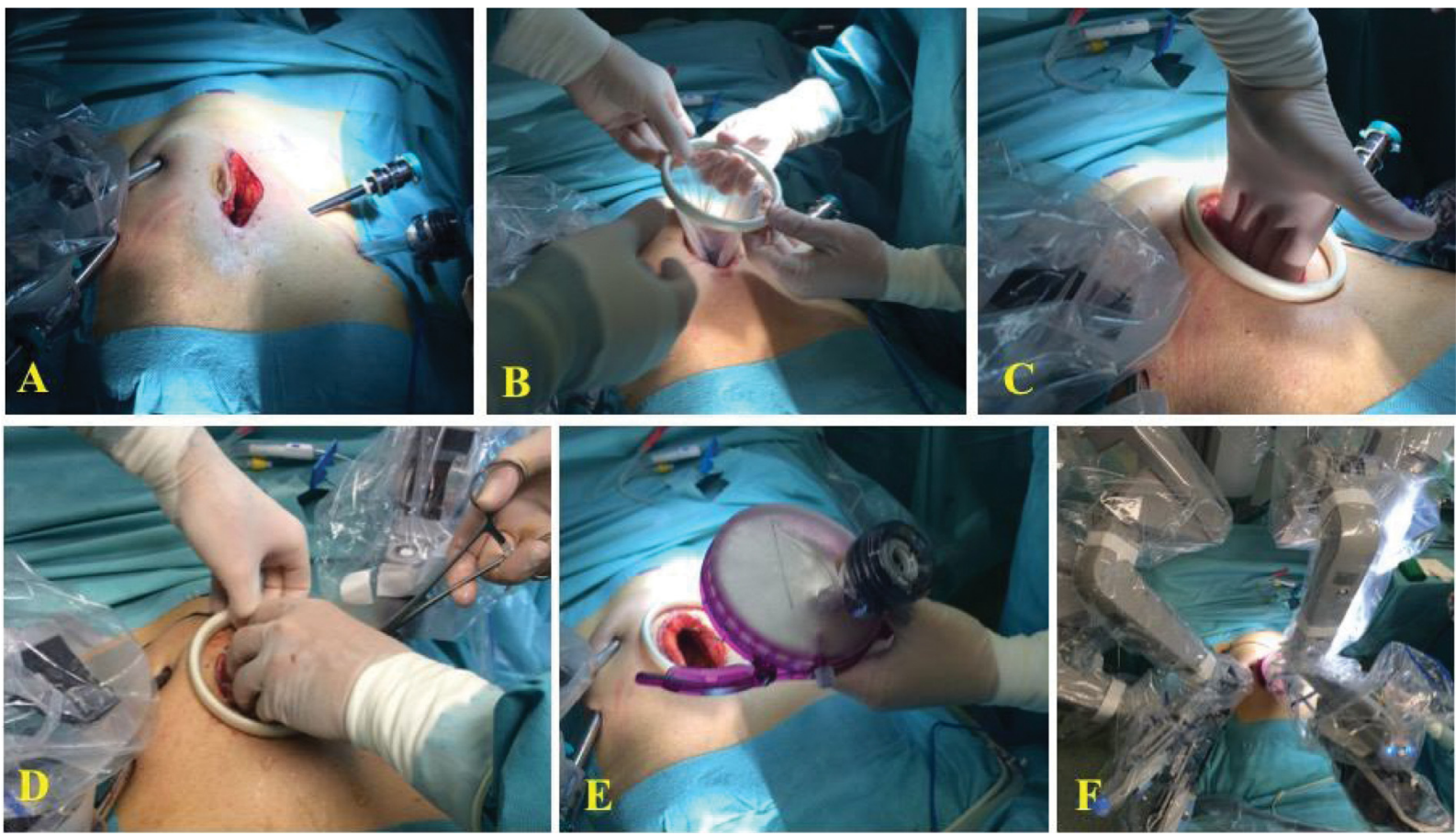

Fig. 1 - (A) A 6-cm linear incision along the umbilicus. (B) GelPOINT wound retractor placement in the linear periumbilical incision. (C) Four-fingerbreadth access to the peritoneal cavity. (D) Introduction of the kidney wrapped in gauze filled with ice slush. (E) GelPOINT cap (with camera trocar) placement. (F) Re-docking of the robot.

subjects, all the surgeons involved had extensively rehearsed the technique on animal models, with proctoring by a more experienced RAKT surgeon during training and when performing the first case(s) in their own center following the standardized approach mentioned above.

\subsection{Statistical analysis}

Data for the demographic characteristics and comorbidities of recipients and for donor characteristics were recorded in a common database. Qualitative variables were described using absolute frequencies and percentages. Quantitative variables were described using the mean, standard deviation (SD), median, and quartiles. The KolmogorovSmirnov test was used to assess the normality of distributions.

Linear relationships between surgical variables (operative and ischemia times) and biomarkers (creatinine $[\mu \mathrm{mol} / \mathrm{l}$ and eGFR $\left.\left[\mathrm{ml} / \mathrm{min} / 1.73 \mathrm{~m}^{2}\right]\right)$ were analyzed using the Pearson test. Follow-up changes in biomarkers were also calculated and analyzed using a Wilcoxon test. Surgical variables were transformed as ordinal variables using tercile values and were compared with biomarkers using a Mann-Whitney $U$ test. For all tests, $p<0.05$ was considered statistically significant. The statistical package R-Studio (V 3.5) was used for statistical analyses.

\section{Results}

\subsection{Descriptive characteristics}

A total of 120 patients were recruited. Demographic data and graft characteristics are summarized in Table 2.

\subsection{Surgical data and functional results}

Surgical data are reported in Table 3. The median estimated blood loss was $150 \mathrm{ml}$, with median hemoglobin of $110 \mathrm{mg} / \mathrm{dl}$ preoperatively and 101, 95 and $98 \mathrm{mg} / \mathrm{dl}$ on POD 1, 3, and 7, respectively. Two patients were converted to
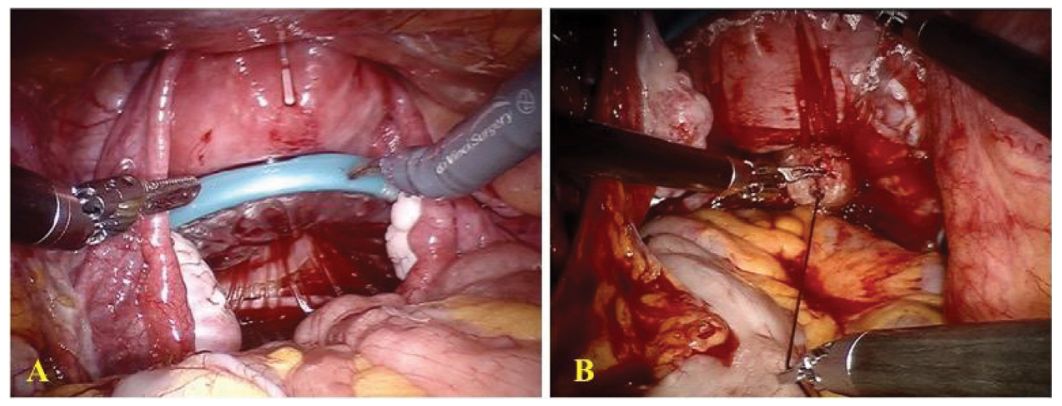

Fig. 2 - (A) Transvaginal GelPOINT placement. (B) Introduction of the graft through the vaginal cavity into the abdominal cavity. 

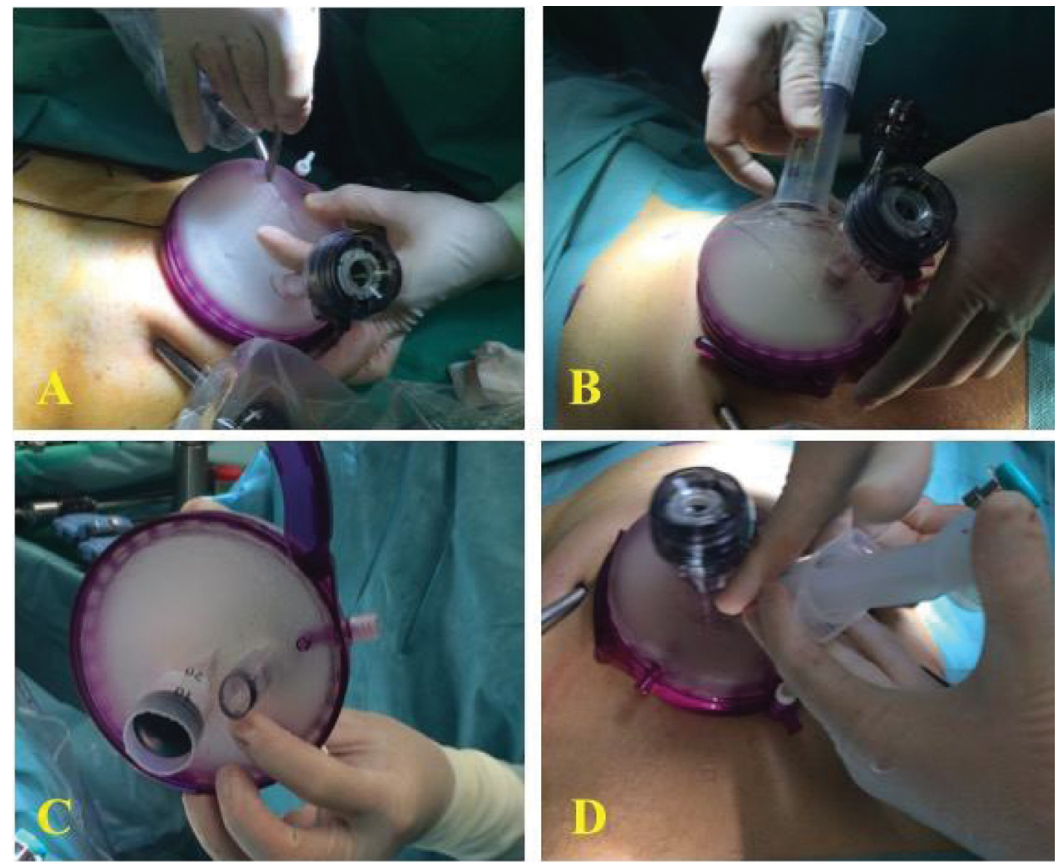

Fig. 3 - (A) A 2-cm incision of the GelPOINT cap with a scalpel. (B,C) Introduction of a modified Toomey tip syringe through the GelPoINT. (D) Introduction of ice slush through the GelPOINT into the pelvis using the modified Toomey tip syringe.

open transplantation owing to low blood flow at Doppler ultrasound evaluation immediately after skin closure and they account for the longest operative times.

Preoperative functional data and postoperative functional results in terms of creatinine and eGFR on POD 1, 3, 7, and 30 are summarized in Table 4 . A significant improvement in renal function (serum creatinine and eGFR) was observed progressively at all postoperative time points. We could not find a correlation between total operative time or rewarming time and postoperative creatinine or eGFR (Tables 5 and 6).

The median VAS pain score was 5, 4, 3, and 2 at 12, 24, 36, and $48 \mathrm{~h}$, after surgery. The median hospital stay was $7 \mathrm{~d}$ (range 4-8 d). The median double-J dwell time was $28 \mathrm{~d}$ (range 14-60). Five cases (4.2\%) of DGF were reported. No arterial or ureteral strictures occurred.
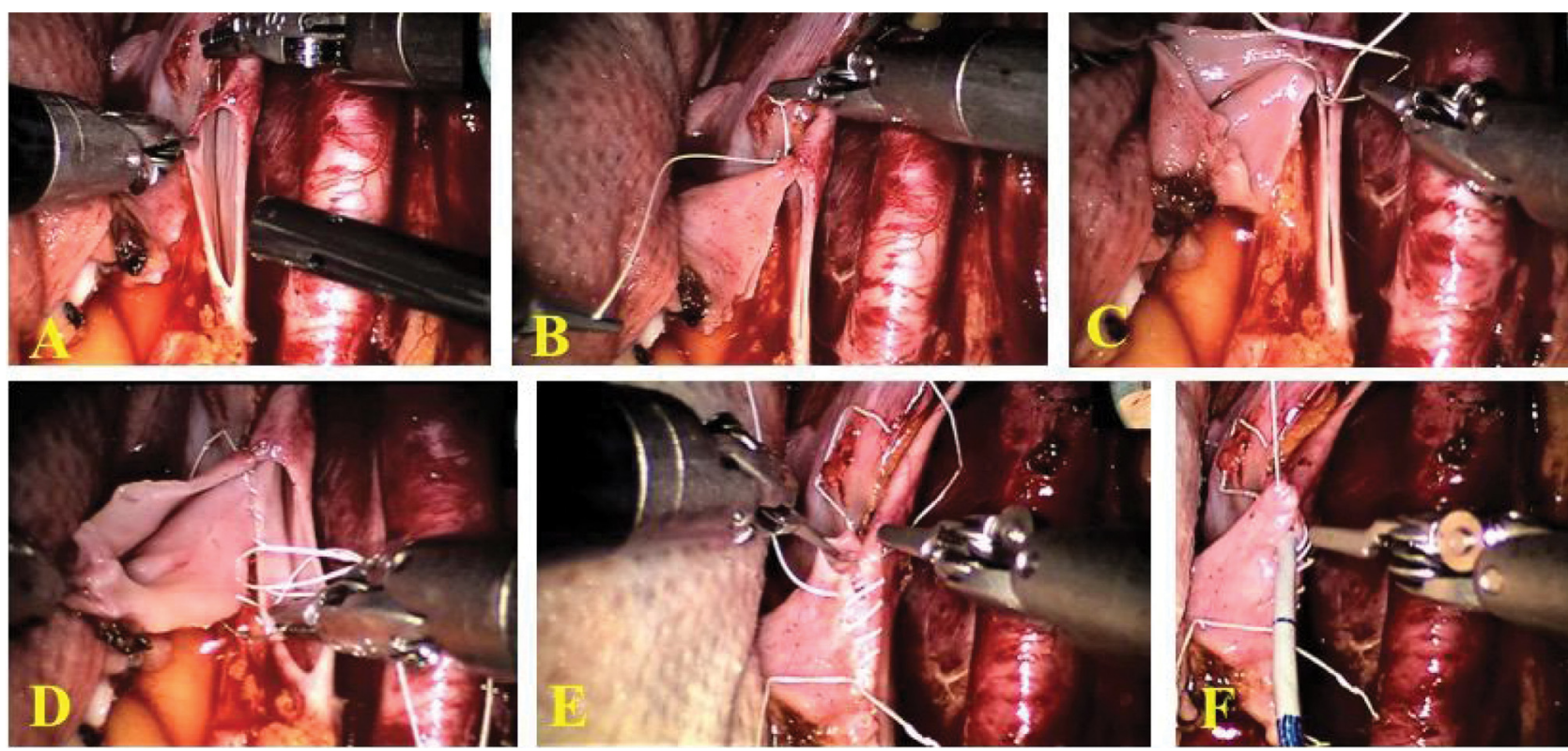

Fig. 4 - Venous anastomosis. (A) External iliac vein incision using robotic scissors. (B-D) The graft renal vein is anastomosed in an end-to-side continuous fashion to the external iliac vein using 6/0 Gore-Tex on a CV-6 needle (W.L. Gore and Associates Inc., Flagstaff, AZ, USA). (E) Venting and checking the water tightness of the venous anastomosis by infusing heparinized saline solution using a $3 F$ ureteral catheter or feeding tube. 


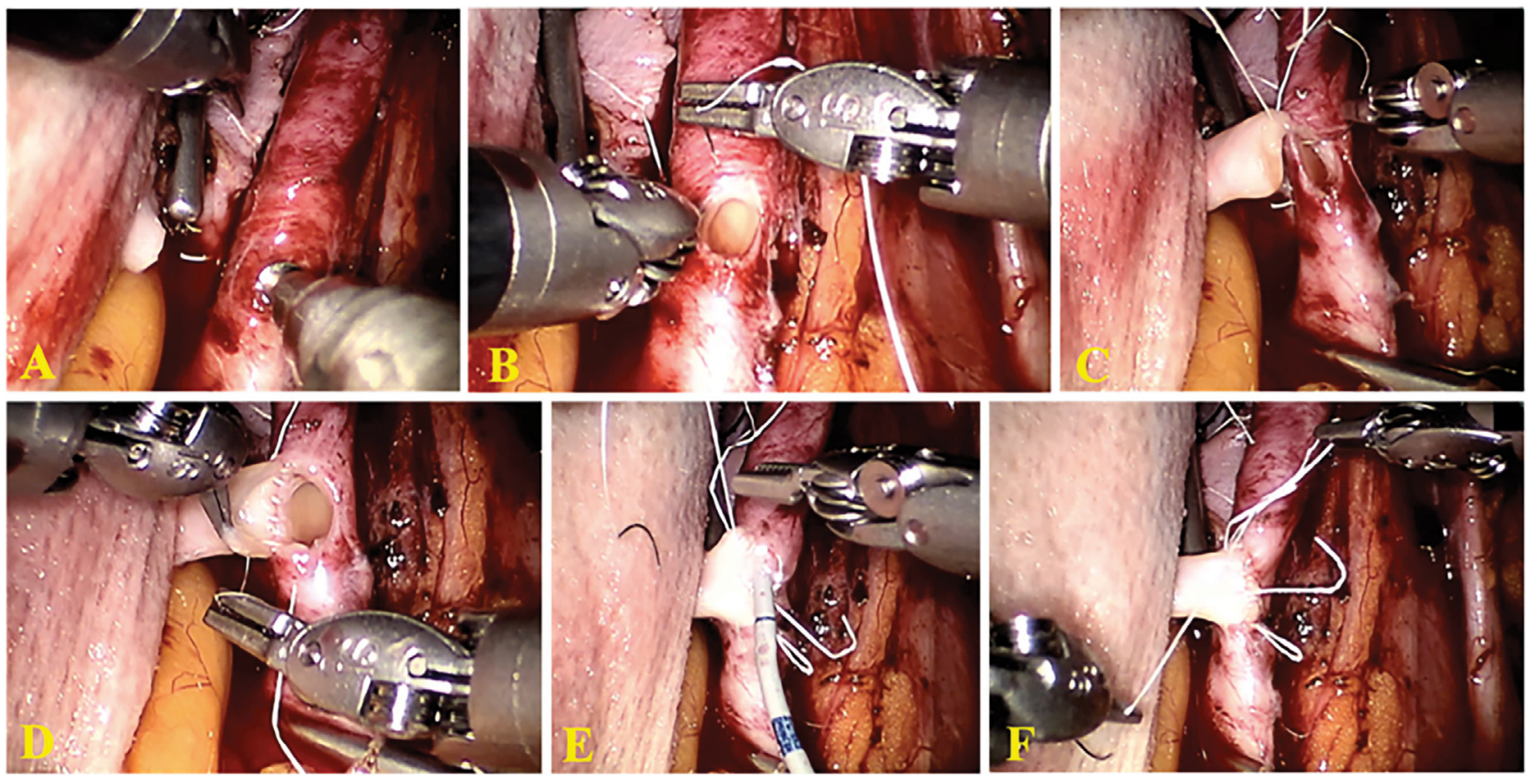

Fig. 5 - Arterial anastomosis. (A) Laparoscopic vascular punch used to create a circular arterial hole. (B) Circular hole in the external iliac artery. (C,D) Arterial anastomosis performed in an end-to-side continuous fashion using 6/0 Gore-Tex on a CV-6 needle (W.L. Gore and Associates Inc.). (E) Venting and checking the water tightness of the arterial anastomosis. (F) Completed arterial anastomosis.

Table 2 - Demographic data and graft characteristics $(n=120)$

\begin{tabular}{ll}
\hline Parameter & \multicolumn{1}{c}{ Result } \\
\hline Sex, $n$ (\%) & \\
Male & $75(62.5)$ \\
\hline Female & $45(37.5)$ \\
\hline Donor relationship, $n$ (\%) & $34(28.3)$ \\
$\quad$ Wife/husband & $20(16.7)$ \\
\hline Parent & $53(44.2)$ \\
\hline Other & $13(10.8)$ \\
\hline Brother/sister & \\
Preemptive, $n$ (\%) & $61(49.6)$ \\
\hline Yes & $59(50.4)$ \\
\hline No & $43.0(19.0)$ \\
\hline Median age at surgery, yr (interquartile range) & $25.2(5.9)$ \\
\hline Median body mass index, kg/m ${ }^{2}$ (interquartile range) & $365(33-420)$ \\
\hline Median dialysis duration, d (interquartile range) & $118: 2$ \\
\hline Donor, live/cadaveric $(n)$ & $103: 17$ \\
\hline Donor side, left/right $(n)$ & $113 / 7$ \\
\hline Vascular anatomy $(n)$ & $118 / 2$ \\
\hline Artery (single/multiple) & $119 / 1$ \\
\hline Vein (single/multiple) & $116 / 4$ \\
\hline Urological anomalies, single/multiple ureter $(n)$ & \\
\hline Graft introduction, transabdominal/transvaginal $(n)$ & \\
\hline
\end{tabular}

Table 3 - Surgical data

\begin{tabular}{lc}
\hline & Median (IQR) \\
\hline Operative time (min) & $250.0(80.0)$ \\
Console time (min) & $160.0(60.0)$ \\
Warm ischemia time (min) & $2.0(2.0)$ \\
Cold time ischemia (min) & $34.0(11.0)$ \\
Rewarming time (min) & $50.0(11.5)$ \\
Total ischemia time (min) & $89.5(21.5)$ \\
Arterial anastomosis time (min) & $19.0(6.5)$ \\
Venous anastomosis time (min) & $20.0(6.5)$ \\
Vascular anastomosis time (min) & $38.0(12.5)$ \\
Ureterovesical anastomosis time (min) & $21.0(7.0)$ \\
Estimated blood loss (cm $\left.{ }^{3}\right)$ & $150(113)$ \\
\hline IQR $=$ interquartile range. & \\
\hline
\end{tabular}

\subsection{Postoperative complication rate}

Postoperative complications, recorded according to the Clavien-Dindo classification, are summarized in Table 7. One case $(0.8 \%)$ of wound infection, three cases $(2.5 \%)$ of ileus, and four cases (3.3\%) of bleeding (three of which required

Table 4 - Preoperative and postoperative functional data

\begin{tabular}{|c|c|c|c|c|c|}
\hline & \multicolumn{5}{|c|}{ Median (interquartile range) } \\
\hline & Preoperative & POD 1 & POD 3 & POD 7 & POD 30 \\
\hline Creatinine $(\mu \mathrm{mol} / \mathrm{l})$ & $517.0(230.4)$ & $288.7(201.5)$ & $155.0(101.2)$ & $131.5(63.0)$ & 130.0 \\
\hline eGFR $\left(\mathrm{ml} / \mathrm{min} / 1.73 \mathrm{~m}^{2}\right)$ & $10.0(6.0)$ & $21.2(14.6)$ & $45.0(32.3)$ & $52.6(24.2)$ & $58.0(27.8)$ \\
\hline
\end{tabular}


Table 5 - Correlation between operating time and analytical variables at POD 1, 7, and 30, and POD 7 - POD 1 and POD 30 - POD 1 differences

\begin{tabular}{|c|c|c|}
\hline & Pearson correlation & $p$ value \\
\hline \multicolumn{3}{|l|}{ POD 1} \\
\hline Creatinine $(\mu \mathrm{mol} / \mathrm{l})$ & -0.114 & 0.237 \\
\hline eGFR $\left(\mathrm{ml} / \mathrm{min} / 1.73 \mathrm{~m}^{2}\right)$ & 0.123 & 0.208 \\
\hline \multicolumn{3}{|l|}{ POD 7} \\
\hline Creatinine $(\mu \mathrm{mol} / \mathrm{l})$ & -0.001 & 0.993 \\
\hline eGFR $\left(\mathrm{ml} / \mathrm{min} / 1.73 \mathrm{~m}^{2}\right)$ & -0.096 & 0.322 \\
\hline \multicolumn{3}{|l|}{ POD 30} \\
\hline Creatinine $(\mu \mathrm{mol} / \mathrm{l})$ & 0.074 & 0.446 \\
\hline eGFR $\left(\mathrm{ml} / \mathrm{min} / 1.73 \mathrm{~m}^{2}\right)$ & -0.101 & 0.297 \\
\hline \multicolumn{3}{|l|}{ Difference POD 1 - POD 7} \\
\hline Creatinine $(\mu \mathrm{mol} / \mathrm{l})$ & 0.161 & 0.094 \\
\hline eGFR $\left(\mathrm{ml} / \mathrm{min} / 1.73 \mathrm{~m}^{2}\right)$ & -0.247 & 0.012 \\
\hline \multicolumn{3}{|l|}{ Difference POD 30 - POD 1} \\
\hline Creatinine $(\mu \mathrm{mol} / \mathrm{l})$ & 0.183 & 0.059 \\
\hline eGFR $\left(\mathrm{ml} / \mathrm{min} / 1.73 \mathrm{~m}^{2}\right)$ & -0.190 & 0.054 \\
\hline
\end{tabular}

blood transfusion), managed conservatively, were observed. One case $(0.8 \%)$ of deep venous thrombosis required anticoagulant drugs. One case $(0.8 \%)$ of lymphocele required percutaneous drainage. Three cases (2.5\%) of transplantectomy due to massive arterial thrombosis were recorded. In five cases (4.2\%), surgical exploration was performed for intraperitoneal hematoma (on POD 2 in 2 cases, POD 3 in 2 cases, and POD 4 in 1 case). None of the patients experienced more than one complication.

\section{Discussion}

Patients with ESRD are generally immunocompromised and fragile. Accordingly, they may gain significant benefits from KT performed using a minimally invasive approach. Minimally invasive techniques in KT (laparoscopic and robotic approaches) have recently been introduced to increase perioperative and postoperative benefits such as

\begin{tabular}{lc}
$\begin{array}{l}\text { Table } 7 \text { - Complications graded according to the Clavien-Dindo } \\
\text { classification for } \mathbf{1 2 0} \text { robot-assisted kidney transplantation } \\
\text { procedures }\end{array}$ & $n(\%)$ \\
\hline Complications & $5(4.2)$ \\
\hline Grade I & $1(0.8)$ \\
\hline Wound infection & $1(0.8)$ \\
\hline Bleeding (observation) & $3(2.5)$ \\
\hline Ileus & $4(3.3)$ \\
\hline Grade II & $1(0.8)$ \\
\hline Deep venous thrombosis & $3(2.5)$ \\
\hline Bleeding requiring blood transfusion & $1(0.8)$ \\
\hline Grade IIIa & $1(0.8)$ \\
\hline Lymphocele & $8(6.7)$ \\
\hline Grade IIIb & $3(2.5)$ \\
\hline Arterial thrombosis & $5(4.2)$ \\
\hline Bleeding requiring surgical exploration & $0(0)$ \\
\hline Grade IV & $0(0)$ \\
\hline Grade V & $\mathbf{1 8}(\mathbf{1 5})$ \\
\hline Total & \\
\hline
\end{tabular}

shorter hospital stay, minimal postoperative pain, shorter convalescence period, fewer wound infections, and better cosmetic results, as observed for minimally invasive radical prostatectomy [2].

Following the first European experience in RAKT [7,8], the robotic approach in KT is now performed in a few European centers as an alternative to the open approach in selected patients. To date, 120 RAKTs, mainly from living donors (98\%), have been performed in this prospective nonrandomized pilot study. Surgical aspects, functional outcomes, and postoperative complication rates were evaluated in this series, which, to the best of our knowledge, is the largest reported on RAKT.

Regarding the surgical aspects, our multicenter prospective study confirms that RAKT can be performed by surgeons with extensive experience in robotic and transplant surgery, even in the early stages of their learning curve. We would like to stress that to obtain such results, the eight surgeons

Table 6 - Correlation between rewarming time and analytical variables at POD 1, 7, and 30, and POD 7 - POD 1 and POD 30 - POD 1 differences

\begin{tabular}{|c|c|c|c|c|}
\hline & \multicolumn{3}{|c|}{$\begin{array}{l}\text { Median (interquartile range) } \\
\text { Rewarming time }\end{array}$} & \multirow[t]{2}{*}{$p$ value } \\
\hline & $\leq 48 \min (n=37)$ & $48-55 \min (n=33)$ & $\geq 55 \min (n=41)$ & \\
\hline \multicolumn{5}{|l|}{$\overline{\text { POD } 1}$} \\
\hline Creatinine $(\mu \mathrm{mol} / \mathrm{l})$ & $305.7(232.6)$ & $291.3(145.0)$ & $279.0(201.1)$ & 0.862 \\
\hline eGFR $\left(\mathrm{ml} / \mathrm{min} / 1.73 \mathrm{~m}^{2}\right)$ & $20.9(16.6)$ & $19.4(8.4)$ & $22.1(15.2)$ & 0.227 \\
\hline \multicolumn{5}{|l|}{ POD 7} \\
\hline Creatinine $(\mu \mathrm{mol} / \mathrm{l})$ & $123.2(56.4)$ & $118.0(63.8)$ & $145.0(62.4)$ & 0.551 \\
\hline eGFR $\left(\mathrm{ml} / \mathrm{min} / 1.73 \mathrm{~m}^{2}\right)$ & $53.0(36.1)$ & $48.0(26.1)$ & $53.0(23.0)$ & 0.112 \\
\hline \multicolumn{5}{|l|}{ POD 30} \\
\hline Creatinine $(\mu \mathrm{mol} / \mathrm{l})$ & $120.0(46.3)$ & $130.0(42.0)$ & $137.0(60.0)$ & 0.587 \\
\hline eGFR $\left(\mathrm{ml} / \mathrm{min} / 1.73 \mathrm{~m}^{2}\right)$ & $64.0(26.0)$ & $51.0(28.0)$ & $55.0(30.4)$ & 0.040 \\
\hline \multicolumn{5}{|l|}{ Difference POD 1 - POD 7} \\
\hline Creatinine $(\mu \mathrm{mol} / \mathrm{l})$ & $-140.8(188.3)$ & $-143.5(82.7)$ & $-140.8(153.2)$ & 0.931 \\
\hline eGFR $\left(\mathrm{ml} / \mathrm{min} / 1.73 \mathrm{~m}^{2}\right)$ & $31.6(27.1)$ & $25.5(25.4)$ & $27.6(26.8)$ & 0.125 \\
\hline \multicolumn{5}{|l|}{ Difference POD 30 - POD 1} \\
\hline Creatinine $(\mu \mathrm{mol} / \mathrm{l})$ & $-136.9(202.5)$ & $-144.0(92.4)$ & $-147.0(201.2)$ & 0.883 \\
\hline eGFR $\left(\mathrm{ml} / \mathrm{min} / 1.73 \mathrm{~m}^{2}\right)$ & $42.8(30.1)$ & $30.2(24.4)$ & $32.9(18.5)$ & 0.012 \\
\hline
\end{tabular}


were trained in an animal laboratory before starting RAKT in humans. Furthermore, the surgeons were proctored during their first four cases to reduce possible mistakes during their learning curve.

In terms of functional outcomes, the most important aspect to consider in KT performed from living donors is patient and graft survival. In a recently published systematic review, no significant differences were observed between the different approaches used (open, laparoscopic, and robotic) in terms of patient and graft survival [13]. For open KT the rate of DGF from living donors has been reported to be up to $4 \%$ [14], while the reported prevalence of arterial graft thrombosis is between $0.5 \%$ and 3.5\% [15]. In our multicenter study, we observed five cases (4.2\%) of DGF and three cases (2.5\%) of arterial thrombosis with graft loss. These results are in line with the literature on open KT, although we note that they could also be related to a learning curve process (with possible technical mistakes) as the lost grafts were at the beginning of the RAKT program. However, the safety of the procedure and graft outcome should be guaranteed even during the learning curve. Therefore, proctoring and careful patient selection (eg, suitable BMI and no previous abdominal surgery) are important during the learning phase. It is important to emphasize that a high level of expertise is required in KT and robotic surgery [16]. Theoretically, particularly during the learning curve, performing RAKTs from deceased donors would possibly reduce the stress related to the surgery. However, recipients of kidneys from deceased donors have a high incidence of arterial atherosclerosis that can potentially compromise arterial clamping and/or vascular anastomosis during this phase. Another important aspect to consider is that it is crucial for success that the surgery always has to be performed by the same dedicated team. This would be very difficult to achieve at times for deceased donor transplantation (ie, night shifts, difficulty in using the robot at night).

So far, it is not completely known whether the intraabdominal temperature during vascular anastomosis has a potentially detrimental effect. When using the robotic approach, maintaining a constant low temperature during the rewarming time is a challenge. The impact of potentially longer duration of rewarming during RAKT on graft function remains unclear [17]. However, to avoid graft impairment during the rewarming time, a regional hypothermia technique for RAKT was described by Menon et al [5] in their IDEAL phase $2 \mathrm{a}$ study. The authors reported use of a gauze jacket filled with ice slush to wrap the kidney during vascular anastomosis, with continuous addition of ice slush for intraperitoneal cooling of the graft. The limitation of this cooling device is the gradual intra-abdominal melting of ice, which might result in renal allograft impairment when there is an extended vascular anastomosis time. Even though it has been confirmed by other authors that this technique is safe and effective $[8,18]$, many concerns remain regarding local and possibly systemic complications related to the use of intraperitoneal cooling to maintain the graft at a constant low temperature. Tuğcu et al [19] reported paralytic ileus as a complication of the use of ice slush, and no ileus occurred when the amount of ice slush was decreased. The three cases of ileus (2.5\%) that we observed could also have been caused by intraperitoneal ice cooling.

The potential damage to the graft as a result of pneumoperitoneum and the associated increase in intraabdominal pressure is not fully known. According to the literature, both renal function and renal blood flow are decreased during pneumoperitoneum, potentially leading to graft impairment. The extent of these reductions depends on preoperative renal function, hydration, and pneumoperitoneum pressure and duration [20].

In our series, we described a wide range of both overall operative and ischemia times. This reflects the different learning curves of the surgeons as well as the time loss for open conversion in two cases and the presence of two deceased donors in our series. Furthermore, we could not find a correlation between operative time (including graft exposure to pneumoperitoneum) or rewarming time and graft function (Tables 5 and 6).

In general, the typical technical advantages of robotic surgery are related to the use of articulated instruments, a three-dimensional view, superb magnification $(12 \times)$, and good surgeon ergonomics. Furthermore, correct use of the da Vinci robotic system possibly provides benefits in terms of patient outcomes, including a significant decrease in blood loss, a low postoperative complication rate, and shorter hospital stay [21]. Oberholzer et al [22] showed the advantages of RAKT in an obese population; from a technical point of view, as reported by Breda et al $[7,9]$, other advantages of RAKT are related to the quality of the vascular anastomosis.

According to a recently published systematic review, minimally invasive techniques in KT, including RAKT, have shown promising results, particularly with regard to complications and recovery [13]. In terms of complications, our experience is in line with that in other RAKT series reported [5]. Unlike open KT [23], lymphocele is an uncommon complication in RAKT. The intraperitoneal window left during RAKT allows natural drainage of lymph into the peritoneal space. In addition, the wound infection rate seems to be very low, with only one case $(0.8 \%)$ reported in a patient with diabetes and hypertension.

Sood et al [18] reported that RAKT is a safe surgical alternative to open $\mathrm{KT}$, reducing postoperative pain and analgesic requirement with a better cosmetic result (Fig. 6). We also observed a low postoperative VAS pain score that rapidly decreased, with a mean hospital stay of $6 \pm 1 \mathrm{~d}$. Length of hospital stay may be considered another possible advantage of RAKT compared to the mean stay for open series (9 \pm 7 d) [24].

One of the limitations of the present study is possible bias in the selection process. The eight centers included in the study are high-volume centers. Despite this, a limited number of recipients were included in the study. This can be explained not only by the inclusion and exclusion criteria but also by the cost limitations of the procedure (some centers had a limited number of procedures accepted per year) and patient preference. Furthermore, not all centers started to recruit patients at the same time. Another 


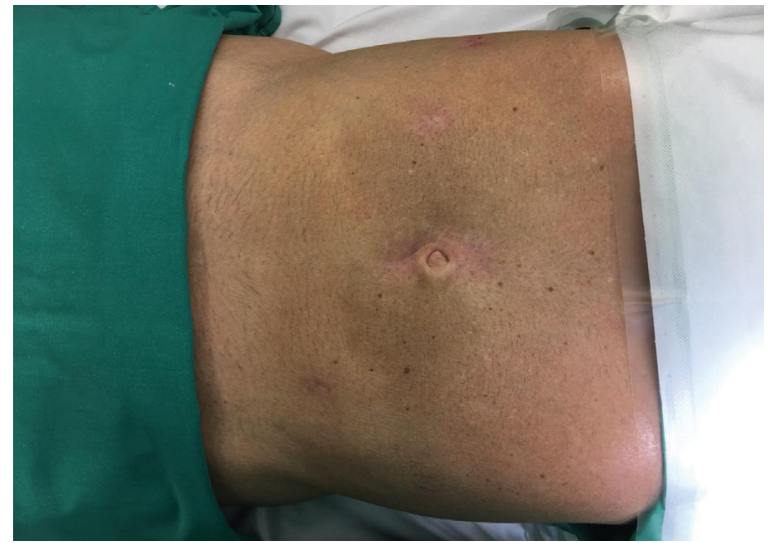

Fig. 6 - Final esthetic result at 2 mo after robot-assisted kidney transplantation.

limitation is the failure to report cosmetic outcomes in a uniform manner. For this reason, no adequate conclusions can be drawn regarding patients' cosmetic satisfaction. From the point of view of cosmetics and postoperative recovery, the transvaginal graft introduction technique described by Doumerc et al [8] and used in our series in four cases (Fig. 2) may be considered an optimal alternative in female recipients. A further limitation of our study is the lack of a control group of patients who underwent open KT from a living donor. A randomized controlled trial and longer follow-up would permit establishment of RAKT as an alternative to open $\mathrm{KT}$.

\section{Conclusions}

To the best of our knowledge, this is the first and largest reported multicenter prospective study on RAKT. In our European patient group, RAKT has been proven to be an advanced application for KT. Surgical data show that RAKT is safe, feasible, and reproducible when performed by surgeons with experience in both robotic and KT surgery. Use of a robotic technique also has low complication rates in selected cases and yields excellent graft function.

Author contributions: Alberto Breda had full access to all the data in the study and takes responsibility for the integrity of the data and the accuracy of the data analysis.

Study concept and design: Breda.

Acquisition of data: Territo, Gausa, Tuğcu, Musquera, Decaestecker, Desender, Janssen, Fornara, Mohammed, Siena, Facundo, Doumerc.

Analysis and interpretation of data: Breda, Territo.

Drafting of the manuscript: Breda, Territo, Decaestecker.

Critical revision of the manuscript for important intellectual content: Breda, Tuğcu, Alcaraz, Decaestecker, Stockle, Fornara, Siena, Serni, Guirado, Doumerc.

Statistical analysis: Territo, Decaestecker.

Obtaining funding: None.

Administrative, technical, or material support: Breda, Gausa.
Supervision: Breda, Doumerc.

Other: None.

Financial disclosures: Alberto Breda certifies that all conflicts of interest, including specific financial interests and relationships and affiliations relevant to the subject matter or materials discussed in the manuscript (eg, employment/affiliation, grants or funding, consultancies, honoraria, stock ownership or options, expert testimony, royalties, or patents filed, received, or pending), are the following: None.

Funding/Support and role of the sponsor: None.

Acknowledgments: We thank Dr. M. Manfredi (Department of Urology, Fundaciò Puigvert) for data collection and database management. We thank Dr. O. Rodríguez-Faba, Dr. J.M. Gaya, and Dr. J. Ponce de León for providing equipment support (Department of Urology, Fundaciò Puigvert). We are also grateful to Dr. S. Mateu (clinical research coordinator at Fundaciò Puigvert) for the institutional review board approval.

\section{References}

[1] Collins AJ, Foley RN, Gilbertson DT, Chen S-C. United States Renal Data System public health surveillance of chronic kidney disease and end-stage renal disease. Kidney Int Suppl 2015;5:2-7.

[2] Herrell SD, Smith JA. Laparoscopic and robotic radical prostatectomy: what are the real advantages? BJU Int 2005;95:3-4.

[3] Hoznek A, Zaki SK, Samadi DB, et al. Robotic assisted kidney transplantation: an initial experience. J Urol 2002;167:1604-6.

[4] Giulianotti P, Gorodner V, Sbrana F, et al. Robotic transabdominal kidney transplantation in a morbidly obese patient. Am J Transplant 2010;10:1478-82.

[5] Menon M, Sood A, Bhandari M, et al. Robotic kidney transplantation with regional hypothermia: a step-by-step description of the Vattikuti Urology Institute-Medanta technique (IDEAL phase 2a). Eur Urol 2014;65:991-1000.

[6] Boggi U, Vistoli F, Signori S, et al. Robotic renal transplantation: first European case. Transpl Int 2011;24:213-8.

[7] Breda A, Gausa L, Territo A, et al. Robotic-assisted kidney transplantation: our first case. World J Urol 2016;34:443-7.

[8] Doumerc N, Roumiguié M, Rischmann P, Sallusto F. Totally robotic approach with transvaginal insertion for kidney transplantation. Eur Urol 2015;68:1103-4.

[9] Breda A, Territo A, Gausa L, et al. Robotic kidney transplantation: one year after the beginning. World J Urol 2017;35:1507-15.

[10] Dindo D, Demartines N, Clavien P-A. Classification of surgical complications: a new proposal with evaluation in a cohort of 6336 patients and results of a survey. Ann Surg 2004;240:205-13.

[11] Levey AS, Coresh J, Greene T, et al. Using standardized serum creatinine values in the modification of diet in renal disease study equation for estimating glomerular filtration rate. Ann Intern Med 2006; 145:247-54.

[12] Schwartz GJ, Muñoz A, Schneider MF, et al. New equations to estimate GFR in children with CKD. J Am Soc Nephrol 2009;20:629-37.

[13] Wagenaar S, Nederhoed JH, Hoksbergen AWJ, Bonjer HJ, Wisselink W, van Ramshorst GH. Minimally invasive, laparoscopic, and robotic-assisted techniques versus open techniques for kidney transplant recipients: a systematic review. Eur Urol 2017;72:205-17.

[14] Redfield RR, Scalea JR, Zens TJ, et al. Predictors and outcomes of delayed graft function after living-donor kidney transplantation. Transpl Int 2016;29:81-7.

[15] Rouvière O, Berger P, Béziat $C$, et al. Acute thrombosis of renal transplant artery: graft salvage by means of intra-arterial fibrinolysis. Transplantation 2002;73:403-9. 
[16] Tzvetanov I, D’Amico G, Benedetti E. Robotic-assisted kidney transplantation: our experience and literature review. Curr Transplant Rep 2017;2:122-6.

[17] Territo A, Mottrie A, Abaza R, et al. Robotic kidney transplantation: current status and future perspectives. Minerva Urol Nefrol 2017;69:5-13.

[18] Sood A, Ghosh P, Jeong W, et al. Minimally invasive kidney transplantation: perioperative considerations and key 6-month outcomes. Transplantation 2015;99:316-23.

[19] Tuğcu V, Şener NC, Şahin S, Yavuzsan AH, Akbay FG, Apaydın S. Robotic kidney transplantation: the Bakırköy experience. Turkish J Urol 2016;42:295-8.

[20] Demyttenaere S, Feldman LS, Fried GM. Effect of pneumoperitoneum on renal perfusion and function: a systematic review. Surg Endosc 2007;21:152-60.
[21] Gastrich MD, Barone J, Bachmann G, Anderson M, Balica A. Robotic surgery: review of the latest advances, risks, and outcomes. J Robot Surg 2011;5:79-97.

[22] Oberholzer J, Giulianotti P, Danielson KK, et al. Minimally invasive robotic kidney transplantation for obese patients previously denied access to transplantation. Am J Transplant 2013;13:721-8.

[23] Mihaljevic AL, Heger P, Dezfouli SA, Golriz M, Mehrabi A. Prophylaxis of lymphocele formation after kidney transplantation via peritoneal fenestration: a systematic review. Transpl Int 2017;30:543-55.

[24] Reddy KS, Mastrangelo M, Johnston T, et al. Recipient outcome following living donor kidney transplantation using kidneys procured laparoscopically. Clin Transplant 2003;17(Suppl 9):44-7. 